\title{
PENGARUH GREEN PRODUCT, GREEN BRAND, DAN GREEN ADVERTISING TERHADAP KEPUTUSAN PEMBELIAN
}

\author{
Gunarso Wiwoho \\ Email: gunarsowiwoho@yahoo.com \\ Sekolah Tinggi Ilmu Ekonomi Putra Bangsa, Kebumen
}

\begin{abstract}
This study aims to determine the effect of Green Product, Green Brand, and Green Advertising on Tupperware Purchasing Decisions in Kebumen. The purpose of this study is to analyze and explain the effect between the independent variable and the dependent variable. The sample in this study are consumers who know, buy, or use Tupperware in the amount of 100 people. Data collection techniques using purposive sampling technique. Validity test shows that all variables in this study are valid. The data is processed using the SPSS 22 for Windows program. Based on the results of the study indicate that the Green Product variable has a significant effect on purchasing decisions. Green Brand has a significant influence on purchasing decisions. Green Advertising has a significant effect on purchasing decisions.
\end{abstract}

Keywords: green product, green brand, green advertising, purchasing decisions

\begin{abstract}
ABSTRAK
Penelitian ini bertujuan untuk mengetahui pengaruh Green Product, Green Brand, dan Green Advertising terhadap Keputusan Pembelian Tupperware di Kebumen. Tujuan penelitian ini adalah menganalisis dan menjelaskan pegaruh antara variabel independen dan variabel dependen. Sampel dalam penelitian ini adalah konsumen yang mengetahui, membeli, ataupun menggunkan Tupperware sejumlah 100 orang. Teknik pengumpulan data menggunakan teknik purposive sampling. Uji validitas menunjukkan bahwa semua variabel dalam penelitian ini adalah valid. Data diolah menggunakan program SPSS 22 for windows. Berdasarkan hasil penelitian menunjukkan bahwa variabel Green Product berpengaruh signfikan terhadap keputusan pembelian. Green Brand berpengaruh signfikan terhadap keputusan pembelian. Green Advertising berpengaruh signfikan terhadap keputusan pembelian.
\end{abstract}

Kata kunci : green product, green brand, green Advertising, dan keputusan pembelian 


\section{PENDAHULUAN}

\section{Latar Belakang}

Dalam beberapa tahun terakhir, muncul berbagai isu yang berkembang di masyarakat global mengenai masalah lingkungan hidup, seperti pencemaran lingkungan, kerusakan hutan, dan pemanasan global. Banyak faktor yang dinilai menjadi penyebab terjadinya masalah-masalah mengenai lingkungan hidup, diantaranya adalah perkembangan industri dan teknologi. Selain memberikan dampak positif, perkembangan industri dan teknologi juga memberikan dampak negatif dalam jangka panjang yang menyebabkan terjadinya kerusakan lingkungan dan pemanasan global. Faktor-faktor penyebab pemanasan global terjadi karena beberapa hal, diantaranya dari sektor ekonomi. Ada beberapa sector di dalam sektor ekonomi, yaitu Sektor persediaan energi menjadi yang paling besar presentasenya, sebesar $25,9 \%$. Berikutnya disusul oleh sektor industri sebesar 19,4\%, sektor kehutanan sebesar $17,4 \%$, sektor transportasi $13,1 \%$, sektor pertanian $13,5 \%$, dan sektor bangunan komersial dan perumahan sebesar 7,9\%. Faktor terakhir yang memiliki presentase paling kecil adalah sektor limbah dan air limbah, yaitu sebesar 2,8\% (www.climatehotmap.org)

Kurangnya kepedulian masyarakat terhadap lingkungan juga menjadi salah satu faktor penyebab munculnya masalah-masalah lingkungan saat ini. Salah satu contoh negara dengan masyarakat yang kurang peduli terhadap lingkungan adalah di Indonesia. Munculnya berbagai ancaman terhadap lingkungan, membuat perusahaan perlu menerapkan suatu konsep bisnis baru dengan menerapkan isu-isu mengenai lingkunganatau disebut green marketing. Menurut Karna et al. (2001:53) Green Marketing didefinisikan sebagai suatu proses manajemen yang bertanggung jawab untuk mengidentifiksi, mengantisipasi, dan memuaskan kebutuhan dari konsumen atau masyarakat secara profitable dan berkelanjutan.

Salah satu produk yang menerapkan Green Marketing adalah Tupperware. Tupperware perusahaan yang bergerak dalam bidang penjualan perabotan rumah tangga. Tupperware perusahaan yang bergerak dalam bidang penjualan perabotan rumah tangga yang berdiri pada tahun 1946, yang didukung lebih dari 150.000 tenaga penjual independen dengan 203 lokasi kantor penjualan (www.tupperware.co.id). Tupperware merupakan produk yang memberikan solusi cerdas, terbuat dari material yang berkualitas yang sudah lulus uji badan kesehatan bahwa aman digunakan. Tupperware sendiri mempunyai banyak varian perabot rumah tangga.

Prestasi gemilang tersebut di awal tahun 2012-2018 diraih oleh Tupperware Indonesia melalui Top Brand Awards 2012-2018. Penghargaan ini merupakan bukti kemampuan Tupperware Indonesia dalam mempertahankan prestasi, mengutamakan profit serta memperlihatkan perkembangan yang cukup pesat dalam penjualan. Di antara beberapa manfaat, produk Tupperware termasuk ramah terhadap lingkungan karena produk Tupperware dapat digunakan kembali dan dapat diwariskan dari satu generasi ke generasi selanjutnya.
Tidak hanya di pusatnya saja penjualan Tupperware terus berkembang, namun di kota Kebumen pun sama, 6 bulan terakhir omset penjualan terus berkembang tiap bulannya.

Tinjauan jurnal dan penelitian terdahulu menggambarkan, jika green product berdampak positif pada keputusan pembelian, seperti dalam penelitian Purnama dan Nurhadi (2014). Selain itu, penelitian yang dilakukan Almaulidta (2015) juga ditemukan adanya pengaruh positif green brand terhadap keputusan pembelian. Dalam penelitian lain, Praharjo et al., (2013) menemukan bahwa green advertising berpengaruh positif terhadap keputusan pembelian.

\section{Batasan Masalah}

Guna menghindari perluasan masalah, dalam penelitian ini penulis membatasi masalah sebagai berikut:

1. Penelitian ini membahas tentang pengaruh green product, green brand, dan green advertising terhadap keputusan pembelian Tupperware di Kebumen.

2. Penelitian ini dilakukan kepada masyarakat Kebumen yang mengetahui, membeli, dan menggunakan Tupperware dengan sampling pada 100 responden.

\section{Penelitian Terdahulu}

\begin{tabular}{|c|c|c|c|}
\hline $\begin{array}{l}\text { Judul } \\
\text { Penelitian }\end{array}$ & $\begin{array}{l}\text { Variabel } \\
\text { Penelitian }\end{array}$ & Metode & $\begin{array}{l}\text { Hasil } \\
\text { Penelitian }\end{array}$ \\
\hline $\begin{array}{l}\text { Pengaruh } \\
\text { Produk } \\
\text { Ramah } \\
\text { lingkungan, } \\
\text { Atribut Merek } \\
\text { Hijau, Iklan } \\
\text { Peduli } \\
\text { Lingkungan } \\
\text { dan Persepsi } \\
\text { Harga } \\
\text { Premium } \\
\text { terhadap } \\
\text { Keputusan } \\
\text { Pembelian } \\
\text { Produk } \\
\text { AMDK }\end{array}$ & $\begin{array}{l}\text { Pengaruh } \\
\text { Produk } \\
\text { Ramah } \\
\text { lingkungan, } \\
\text { Atribut } \\
\text { Merek } \\
\text { Hijau, Iklan } \\
\text { Peduli } \\
\text { Lingkungan } \\
\text { dan Persepsi } \\
\text { Harga } \\
\text { (Variabel } \\
\text { Indepndent) } \\
\text { keputusan } \\
\text { Pembelian } \\
\text { (Variabel } \\
\text { Dependent) }\end{array}$ & $\begin{array}{l}\text { Analisis } \\
\text { Regresi } \\
\text { Bergand } \\
\text { a, Uji t } \\
\text { dan Uji } \\
\text { F }\end{array}$ & $\begin{array}{l}\text { Produk ramah } \\
\text { lingkungan,atr } \\
\text { ibut } \\
\text { hijau,iklan } \\
\text { peduli } \\
\text { lingkungan } \\
\text { dan persepsi } \\
\text { harga } \\
\text { premium } \\
\text { secara } \\
\text { bersama-sama } \\
\text { berpengaruh } \\
\text { positif } \\
\text { terhadap } \\
\text { keputusan } \\
\text { pembelian } \\
\text { produk } \\
\text { AMDK } \\
\text { melalui uji t } \\
\text { dan uji F }\end{array}$ \\
\hline $\begin{array}{l}\text { Pengaruh } \\
\text { Green Product } \\
\text { dan Green } \\
\text { Advertising } \\
\text { terhadap } \\
\text { Keputusan } \\
\text { Pembelian } \\
\text { Konsumen } \\
\text { (Survey pada } \\
\text { Konsumen } \\
\text { Supermarket } \\
\text { Superindor } \\
\text { Cabang Metro }\end{array}$ & $\begin{array}{l}\text { Green } \\
\text { Product dan } \\
\text { Green } \\
\text { Advertising } \\
\text { (variabel } \\
\text { independent } \\
\text { ) Keputusan } \\
\text { Pembelian } \\
\text { (variabel } \\
\text { dependent) }\end{array}$ & $\begin{array}{l}\text { Analisis } \\
\text { Regresi } \\
\text { Bergand } \\
\text { a, Uji t } \\
\text { dan Uji } \\
\text { F }\end{array}$ & $\begin{array}{l}\text { Green product } \\
\text { dan green } \\
\text { advertising } \\
\text { secara parsial } \\
\text { berpengaruh } \\
\text { terhadap } \\
\text { signifikan } \\
\text { terhadap } \\
\text { keputusan } \\
\text { pembelian }\end{array}$ \\
\hline
\end{tabular}




\begin{tabular}{|c|c|c|c|}
\hline $\begin{array}{l}\text { Pengaruh } \\
\text { Green } \\
\text { Advertising } \\
\text { terhadap } \\
\text { Persepsi } \\
\text { Tentang } \\
\text { Green Brand } \\
\text { dan } \\
\text { Keputusan } \\
\text { Pembelian } \\
\text { (Survei Pada } \\
\text { Mahasiswa } \\
\text { Fakultas Ilmu } \\
\text { Administrasi } \\
\text { Angkatan } \\
\text { 2010/2011 } \\
\text { Universitas } \\
\text { Brawijaya } \\
\text { Konsumen } \\
\text { Air Minum } \\
\text { Kemasan } \\
\text { Merek Ades) }\end{array}$ & $\begin{array}{l}\text { Green } \\
\text { Advertising } \\
\text { (variabel } \\
\text { mediasi) } \\
\text { Green } \\
\text { Brand } \\
\text { (variabel } \\
\text { Independent } \\
\text { ) keputusan } \\
\text { pembelian } \\
\text { (variabel } \\
\text { dependent) }\end{array}$ & $\begin{array}{l}\text { Analisis } \\
\text { Regresi } \\
\text { Bergand } \\
\text { a, Uji t } \\
\text { dan Uji } \\
\text { F }\end{array}$ & $\begin{array}{l}\text { variabel green } \\
\text { advertising } \\
\text { berpengaruh } \\
\text { positif } \\
\text { terhadap } \\
\text { Persepsi, } \\
\text { persepsi } \\
\text { berpengaruh } \\
\text { terhadap } \\
\text { Green Brand, } \\
\text { dan Green } \\
\text { Brand } \\
\text { berpengaruh } \\
\text { positif } \\
\text { terhadap } \\
\text { keputusan } \\
\text { pembelian }\end{array}$ \\
\hline $\begin{array}{l}\text { Pengaruh } \\
\text { Green Product } \\
\text { dan Green } \\
\text { Advertising } \\
\text { terhadap } \\
\text { Keputusan } \\
\text { Pembelian } \\
\text { Konsumen } \\
\text { Sepeda Motor } \\
\text { Vario Techno } \\
125 \text { PGM F1 } \\
\text { di Purworejo }\end{array}$ & $\begin{array}{l}\text { Green } \\
\text { Product dan } \\
\text { Green } \\
\text { Advertising } \\
\text { (variabel } \\
\text { independent } \\
\text { ) } \\
\text { kepuasan } \\
\text { nasabah } \\
\text { (variabel } \\
\text { depedent) }\end{array}$ & $\begin{array}{l}\text { Analisis } \\
\text { Regresi } \\
\text { Bergand } \\
\text { a, Uji t } \\
\text { dan Uji } \\
\text { F }\end{array}$ & $\begin{array}{l}\text { Green Product } \\
\text { dan Green } \\
\text { Advertising } \\
\text { berpengaruh } \\
\text { positif } \\
\text { terhadap } \\
\text { keputusan } \\
\text { pembelian } \\
\text { sepeda motor } \\
\text { Honda Vario } \\
\text { Techno } 125 \\
\text { PGM F }\end{array}$ \\
\hline
\end{tabular}

\section{Kerangka Pemikiran}

Gambar 1

\section{Gambar II.I}

\section{Kerangka Pemikiran}

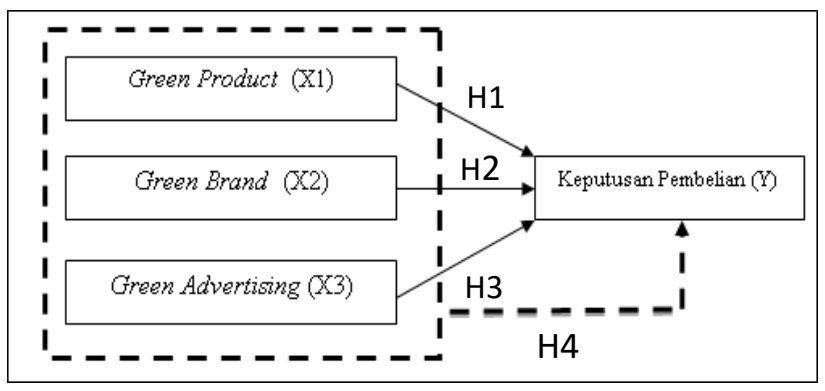

Sumber : Dikembangkan dalam penelitian ini,2019

\section{Hipotesis}

Hipotesis dalam penelitian ini adalah sebagai berikut :

H1 : Ada pengaruh Green Product (X1) berpengaruh terhadap Keputusan Pembelian (Y) Tupperware di Kebumen.

H2 : Ada pengaruh Green Brand (X2) berpengaruh terhadap Keputusan Pembelian (Y) Tupperware di Kebumen.
H3 : Ada pengaruh Green Advertising (X3) berpengaruh terhadap Keputusan Pembelian (Y) Tupperware di Kebumen.

H4 : Ada pengaruh Green Product (X1), Green Brand (X2), Green Advertising (X3) berpengaruh secara bersama-sama terhadap Keputusan Pembelian (Y) Tupperware di Kebumen.

\section{METODE}

\section{Variabel dan Definisi Operasional Variabel}

\section{Keputusan Pembelian (Y)}

Menurut Amirullah (2002) keputusan pembelian didefinisikan sebagai suatu proses dimana konsumen melakukan penilaian terhadap berbagai alternatif pilihan dan memilih salah satu alternatif yang diperlukan berdasarkan pertimbangan-pertimbangan tertentu.

Tabel 2

Indikator Keputusan Pembelian (Y) pada Kuisioner

\begin{tabular}{|c|c|c|c|}
\hline $\begin{array}{l}\mathbf{N} \\
\mathbf{0}\end{array}$ & Indikator & $\begin{array}{l}\text { Distribusi } \\
\text { butir ke }\end{array}$ & $\begin{array}{l}\text { Jum } \\
\text { lah }\end{array}$ \\
\hline 1. & $\begin{array}{ll}\text { Perhatian } & \text { terhadap } \\
\text { lingkungan } & \end{array}$ & 5 & 1 \\
\hline 2. & Harga & 1,2 & 2 \\
\hline 3. & Kualitas & 3 & 1 \\
\hline 4. & $\underline{\text { Kemasan }}$ & $\underline{4}$ & $\underline{1}$ \\
\hline
\end{tabular}

Sumber : Data Primer Diolah, 2019

\section{Green Product $\left(\mathrm{X}_{1}\right)$}

Menurut Junaedi (2005) dalam Shaputra (2013:51) mendefinisikan, Green product atau produk hijau

adalah produk yang berwawasan lingkungan yang dirancang dan diproses dengan suatu cara untuk mengurangi efek- efek yang dapat mencemari lingkungan, baik dalam produksi,pendistribusian dan pengkonsumsiannya. Indikator variabel ini dibatasi oleh

Tabel 3

Indikator Green Product $\left(\mathrm{X}_{1}\right)$ pada Kuisioner

\begin{tabular}{llcc}
\hline No & Indikator & $\begin{array}{c}\text { Distribusi } \\
\text { butir ke }\end{array}$ & $\begin{array}{l}\text { Jum } \\
\text { lah }\end{array}$ \\
\cline { 3 - 3 } 1 & Persepsi Produk & 1,5 & 2 \\
2 & Kemasan & 2,4 & 2 \\
3 & Komposisi Isi & 3 & 1 \\
\hline & Jumlah & & $\underline{5}$ \\
\hline
\end{tabular}

Sumber : Data Primer Diolah, 2019

\section{Green Brand $\left(\mathrm{X}_{2}\right)$}

Menurut Keller et al., (1993) green brand atau merek hijau merupakan citra merek hijau yang mendapat persepsi dan terasosiasi dibenak konsumen yang terkait dengan penawaran produk atau jasa. Variabel ini dibatasi dengan : 
Tabel 4

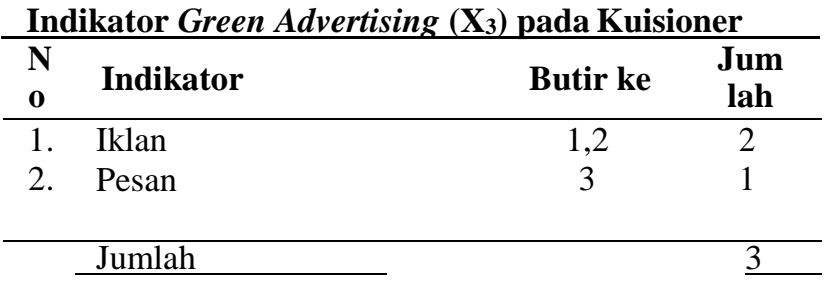

Sumber : Data Primer Diolah, 2019

\section{Populasi dan Sampel}

Menurut Sugiyono (2008:115), populasi adalah wilayah generalisasi yang terdiri dari objek atau subjek yang akan menjadi kuantitas dan karakteristik tertentu yang ditetapkan oleh penelitian untuk dipelajari dan kemudian ditarik kesimpulannya. Populasi dalam penelitian ini adalah seluruh masyarakat yang mengetahui, membeli, dan menggunkan Tupperware.

Sampel adalah sebagian dari jumlah dan karakteristik yang dimiliki oleh populasi tersebut (Sugiyono, 2008:73). Penelitian ini menggunakan teknik sampling nonprobability sampling, yaitu teknik pengambilan sampel yang tidak memberi peluang/kesempatan sama bagi setiap unsur atau anggota populasi untuk dipilih menjadi sampel. populasi diambil sebagai sampel dengan jumlah 100 orang.

\section{Jenis Data dan Teknik Analisis Data}

\section{Jenis Data}

\section{Data Primer}

Data yang diperoleh secara langsung dari obyek penelitian. Data primer dalam penelitian ini diperoleh dari hasil penyebaran kuesioner dengan skala likert kepada responden. Responden disini adalah masyarakat Kebumen yang mengetahui, membeli, dan menggunakan Tupperware.

\section{Data Sekunder}

Data yang diperoleh melalui studi kepustakaan, catatancatatan, peraturan-peraturan dan kebijakan.

\section{Teknik Analisis Data}

\section{Analisis Data Deskriptif}

Analisis deskriptif dilakukan dengan merinci dan menjelaskan mengenai karakterisik responden dan disajikan dalam bentuk tabel

\section{Analisis Data Kuantitatif}

Teknik analisis data kuantitatif merupakan teknik analisis dengan menghitung dan menganalisa hasil perhitungan data dengan software SPSS 22.00 melalui uji berikut :

1) Uji Validitas Instrumen

Uji validitas digunakan untuk mengukur tingkat kemampuan suatu instrumen guna mengukur sesuatu menjadi sasaran pokok pengukuran yang dilakukan dengan instrumen tersebut (Sutrisno Hadi, 2004).
Dengan metode Pearson Product moment, apabila $\mathrm{r}$ hitung $>\mathrm{r}$ tabel $(\alpha=0,05)$, maka item tersebut valid.

2) Uji Reliabilitas Instrumen

Uji reliabilitas digunakan untuk menguji apakah kuesioner yang dipakai sudah reliable atau handal, sehingga bisa diandalkan dalam memperoleh informasi. Dengan metode Cronbach Alpha, bila koefisien Cronbach Alpha $\geq 0,6$, maka variabel reliabel

3) Uji Asumsi Klasik dengan :

a. Uji Normalitas data

Pengujian ini untuk mengetahui apakah dalam sebuah model regresi variabel bebas, variabel terikat atau keduanya mempunyai distribusi normal atau tidak. Data menyebar di sekitar garis diagonal dan mengikuti arah garis diagonal, maka model regresi tersebut memenuhi asumsi normalitas

b. Uji Multikolinieritas Data

Pengujian ini dimaksudkan untuk mengetahui apakah dalam persamaan regresi ditemukan adanya korelasi antara variabel terikat dengan syarat mempunyai nilai VIF di sekitar 1 dan atau mempunyai angka tolerance mendekati angka 1.

c. Uji Heterokedastisitas

Pengujian ini untuk menguji apakah model regresi terjadi ketidaksamaan varian residual dari satu pengamatan ke pangamatan yang lain. Jika tidak terdapat pola yang jelas, serta titik-titik pada grafik menyebar diatas dan dibawah angka 0 (nol) pada sumbu Y, maka tidak terjadi heteroskedastisitas.

4) Pengujian Regresi Linier Berganda

Analisis dalam penelitian ini menggunakan regresi linier berganda yang dirumuskan untuk mencari pengaruh antar variabel sebagai berikut:

$\mathbf{Y}=\mathbf{a}+\mathbf{b}_{1} \mathbf{X}_{1}+\mathbf{b}_{2} \mathbf{X}_{2}+\mathbf{b}_{3} \mathbf{X}_{3}+\mathbf{e}$

Keterangan :

$\mathrm{Y}=$ Kepuasan kerja

$\mathrm{a}=$ Konstanta

$\mathrm{b}_{1}, \mathrm{~b}_{2}, \mathrm{~b}_{3}=$ Koefisien regresi

$\mathrm{X}_{1}=$ Variabel iklim organisasi

$\mathrm{X}_{2}=$ Variabel motivasi intrinsik

$\mathrm{X}_{3}=$ Variabel motivasi ekstrinsik

$\mathrm{e}=$ error

5) Uji Hipotesis dengan :

a. Uji t

Uji t menunjukkan seberapa jauh pengaruh satu variabel independen secara individual dalam menerangkan variasi variabel independen. Jika t 
hitung lebih besar dari $\mathrm{t}$ tabel, maka disebut berpengaruh signifikan

b. Uji F

Uji F menunjukkan seberapa jauh pengaruh variabel independen secara bersamaan dalam menerangkan variasi variabel independen. Jika $\mathrm{F}$ hitung lebih besar dari $\mathrm{F}$ tabel, maka disebut berpengaruh signifikan

6) Koefisien Determinasi $\left(\mathrm{R}^{2}\right)$

Koefisien determinasi $\left(\mathrm{R}^{2}\right)$ adalah angka yang menunjukkan proporsi variabel dependen yang dijelaskan oleh variabel independen, atau prosentase perubahan variabel dependen yang dapat dijelaskan oleh variabel independen.

\section{HASIL DAN PEMBAHASAN}

\section{ANALISIS DESKRIPTIF}

Berikut hasil analisis deskiptif pada karakterisik responden yang diteliti :

Tabel 7

Klasifikasi Responden

\begin{tabular}{llll}
\hline Jenis Kelamin $(\%)$ & \multicolumn{3}{l}{ Usia $(\%)$} \\
\hline Laki-laki & 21 & $18-20$ Thn & 13 \\
Perempuan & 79 & $21-30$ thn & 63 \\
& & $31-40$ thn & 24 \\
\hline
\end{tabular}

Sumber : Data primer diolah, 2019

\section{ANALISIS KUANTITATIF}

Berikut hasil analisis kuantitatif pada kuisioner adalah:

\section{Uji Validitas Instrumen}

Berikut hasil analisis validitas pada kuisioner adalah:

\section{Tabel 8}

Uji Validitas

\begin{tabular}{|c|c|c|c|}
\hline \multicolumn{4}{|c|}{ Green Product } \\
\hline Butir & r hitung & $\mathrm{r}$ tabel & $\underline{\text { Status }}$ \\
\hline 1 & 0,496 & 0,1975 & Valid \\
\hline 2 & 0,750 & 0,1975 & Valid \\
\hline 3 & 0,746 & 0,1975 & Valid \\
\hline 4 & 0,683 & 0,1975 & Valid \\
\hline 5 & 0,774 & 0,1975 & Valid \\
\hline
\end{tabular}

\section{Green Brand}

\begin{tabular}{lrrl}
1 & 0,612 & 0,1975 & Valid \\
2 & 0,638 & 0,1975 & Valid \\
3 & 0,660 & 0,1975 & Valid \\
4 & 0,756 & 0,1975 & Valid \\
5 & 0,535 & 0,1975 & Valid \\
6 & 0,729 & 0,1975 & Valid \\
\hline \multicolumn{4}{l}{ Green Advertising } \\
\hline 1 & 0,663 & 0,1975 & Valid \\
2 & 0,869 & 0,1975 & Valid \\
3 & 0,845 & 0,1975 & Valid \\
\hline \multicolumn{2}{l}{ Keputusan Pembelian } & & \\
\hline 1 & 0,714 & 0,1975 & Valid \\
2 & 0,576 & 0,1975 & Valid \\
3 & 0,643 & 0,1975 & Valid
\end{tabular}

\begin{tabular}{llrl}
4 & 0,578 & 0,1975 & Valid \\
5 & $\underline{0,595}$ & $\underline{0,1975}$ & Valid \\
\cline { 1 - 1 } Sumber & $\underline{\text { Data Primer Diolah, 2019 }}$ &
\end{tabular}

Semua tabel uji Validitas menjelaskan bahwa $\mathrm{r}$ hitung lebih besar dari $r$ tabel, sehingga item pernyataan yang dipakai pada semua variabel dinyatakan valid (sah).

\section{Uji Reliabilitas Instrumen}

Berikut hasil uji reliabilitas pada kuisioner adalah:

Tabel 9

Uji Reliabilitas

\begin{tabular}{lccc}
\hline \multicolumn{1}{c}{ Variabel } & $\begin{array}{c}\text { Nilai Alpha } \\
\text { Cronbach }\end{array}$ & $\begin{array}{c}\text { Nilai } \\
\text { Min }\end{array}$ & Status \\
\hline $\begin{array}{l}\text { Keputusan } \\
\text { Pembelian }\end{array}$ & 0,60 & 0,605 & Reliabel \\
Green Advertising & 0,60 & 0,699 & Reliabel \\
Green Brand & 0,60 & 0,729 & Reliabel \\
Green Product & 0,60 & 0,726 & Reliabel \\
\hline
\end{tabular}

Sumber : Data Primer Diolah, 2019

Berdasarkan tabel di atas, dijelaskan bahwa seluruh variabel yang dipakai dalam penelitian ini dinyatakan reliabel (handal) karena nilai $\mathrm{r}$ alpha cronbach hasil perhitungan lebih besar dari 0,6.

\section{Uji Asumsi Klasik}

Uji asumsi klasik terdiri atas :

\section{a. Multikolinieritas}

Tabel 10

Uji Multikolinieritas Coefficients $^{a}$

\begin{tabular}{|c|c|c|c|}
\hline \multirow{2}{*}{ Model } & & \multicolumn{2}{|c|}{ Collinearity Statistics } \\
\hline & & Tolerance & VIF \\
\hline 1 & (Constant) & & \\
\hline & GREEN PRO & 381 & 2,626 \\
\hline & GREEN BRAND & ,400 & 2,499 \\
\hline & GREEN ADVERTISING & 609 & 1,641 \\
\hline
\end{tabular}

a. Dependent Variable: KEPUTUSAN PEMBELIAN Sumber : Data Primer Diolah, 2019

Tabel coefficients di atas dapat dijelaskan bahwa pada bagian collinearity statistic menunjukan angka VIF dibawah 10 dan tolerance di atas 0,1, artinya VIF dan tolerance di sekitar angka 1, karena itu model regresi ini tidak terdapat multikolinieritas.

\section{b. Heterokedastisitas}

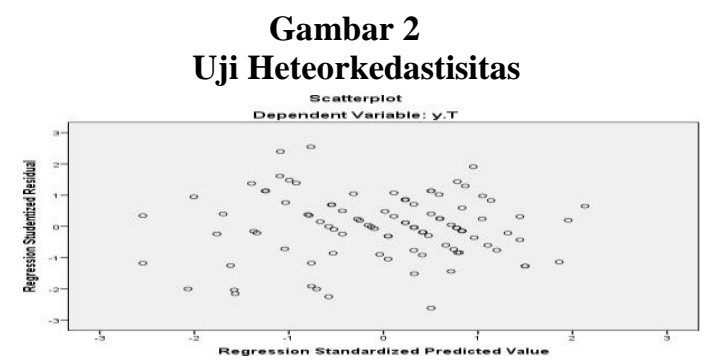

Sumber : Data Primer Diolah, 2019 
Gambar diatas menunjukan bahwa bulatan-bulatan kecil tidak memiliki pola tertentu, seperti titik-titik atau bulatan yang membentuk suatu pola tertentu yang teratur dan tidak ada pola yang jelas sehingga dapat disimpulkan model regresi dalam penelitian ini tidak terjadi gejala heteroskedastisitas.

\section{c. Normalitas Data}

Gambar 3
Uji Normalitas

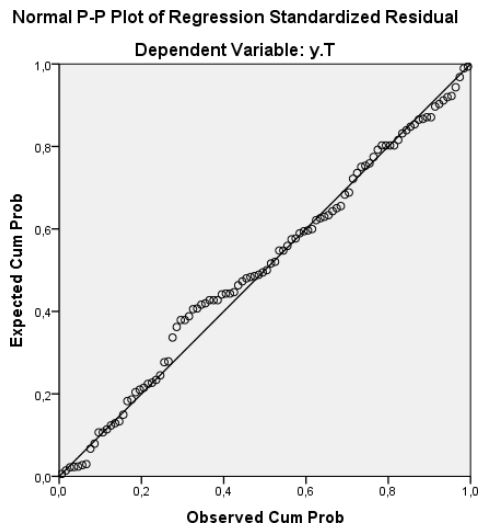

Sumber : Data Primer Diolah, 2019

Berdasarkan gambar uji normalitas diatas terlihat bahwa data menyebar disekitar garis diagonal dan mengikuti arah garis diagonal. Maka model regresi memenuhi asumsi normalitas.

\section{Regresi Linier Berganda dan Uji t}

Berikut hasil uji regresi linier berganda:

Tabel 11

Uji Regresi Linier Berganda

\begin{tabular}{|c|c|c|c|c|}
\hline \multicolumn{5}{|c|}{ Unstandardized Coefficients } \\
\hline Model & B & Std. Error & $\mathrm{t}$ & Sig. \\
\hline 1 (Constant) & 1,932 & ,798 & 2,421 & 017 \\
\hline $\begin{array}{l}\text { GREEN } \\
\text { PRODUCT }\end{array}$ & ,415 & ,075 & 5,522 & ,000 \\
\hline GREEN BRAND & ,202 & ,069 & 2,926 & ,004 \\
\hline $\begin{array}{l}\text { GREEN } \\
\text { ADVERTISING }\end{array}$ & ,340 &, 086 & 3,943 & ,000 \\
\hline
\end{tabular}

a. Dependent Variable: KEPUASAN KERJA

Sumber : Data Primer Diolah, 2019

Berdasarkan tabel di atas, maka dapat dibuat persamaan regresinya sebagai berikut :

$$
\mathrm{Y}=1,932+0,415 \mathrm{X}_{1}+0,202 \mathrm{X}_{2}+0,340 \mathrm{X}_{3}+\mathrm{e}
$$

Hasil regresi menunjukkan jika semua variabel bebas berpengaruh positif terhadap keputusan pembelian. Jika green product, green brand, dan green advertising meningkat maka keputusan pembelian Tupperware juga akan meningkat.

Hasil uji t menunjukkan :

1. Hasil uji t menunjukan bahwa probabilitas signifikansi untuk variabel Green Product $\left(\mathrm{X}_{1}\right)$ sebesar 0,000 $<0,05$ dan hasil perhitungan diperoleh angka $t_{\text {hitung }}$ sebesar 3,943 $<\mathrm{t}_{\text {tabel }}$ sebesar 1,985. Hasil ini yang signifikan terhadap Keputusan Pembelian pada Tupperware di Kebumen.

2. Hasil uji $\mathrm{t}$ menunjukan bahwa probabilitas signifikansi untuk variabel label halal $\left(\mathrm{X}_{2}\right)$ sebesar $0,000<0,05$ dan hasil perhitungan diperoleh angka $\mathrm{t}_{\text {hitung }}$ sebesar 2,926 < $\mathrm{t}_{\text {tabel }}$ sebesar 1,985. Hasil ini menyatakan Green Brand mempunyai pengaruh yang signifikan terhadap Keputusan Pembelian pada Tupperware di Kebumen.

3. Hasil uji $\mathrm{t}$ menunjukan bahwa probabilitas signifikansi untuk variabel Green Advertising $\left(\mathrm{X}_{3}\right)$ sebesar $0,00<0,05$ dan hasil perhitungan diperoleh angka $\mathrm{t}_{\text {hitung }}$ sebesar 5,522 $>\mathrm{t}_{\text {tabel }}$ sebesar 1,985. Hasil ini menyatakan Green Advertising mempunyai pengaruh yang signifikan terhadap Keputusan Pembelian Tupperware di Kebumen.

\section{Uji F}

Berikut hasil uji simultan:

Tabel 17

Uji F

\begin{tabular}{lrcrl} 
Model & Sum Of Squares & Df & \multicolumn{1}{c}{ Mean } \\
Square & Sig. \\
\hline Regression & 507,503 & 3 & 169,168 &, $000^{\mathrm{b}}$ \\
Residual & 179,887 & 96 & 1,874 & \\
Total & 687,390 & 99 & & \\
\hline
\end{tabular}

a. Dependent Variable: KEPUTUSAN PEMBELIAN

Sumber : Data Primer Diolah, 2019

Berdasarakan hasil olah data diatas, dipeproleh $\mathrm{F}_{\text {hitung }}$ adalah 90,280 dengan tingkat signifikansi ,000. Karena probabilitas $(0,000)$ jauh lebih kecil dari 0,05 ,sehingga bisa dikatakan bahwa model regresi linear yang diestimasi pada penelitian ini layak digunakan untuk menjelaskan pengaruh variabel Green Product, Green Brand, dan Green Advertising berpengaruh signifikan secara bersama-sama terhadap keputusan pembelian Tupperware.

\section{Koefisien Determinasi $\left(\mathbf{R}^{2}\right)$}

Berikut hasil $\mathrm{R}^{2}$.

Tabel 17

Uji R Square

Model Summary

\begin{tabular}{|c|c|c|c|c|}
\hline Model & $\mathrm{R}$ & $\begin{array}{c}\mathrm{R} \\
\text { Square }\end{array}$ & $\begin{array}{l}\text { Adjusted R } \\
\text { Square }\end{array}$ & Std. Error of the Estimate \\
\hline
\end{tabular}

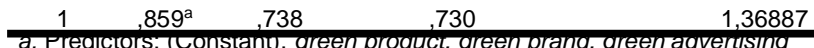




\section{Pembahasan \\ $H_{1}$ : Iklim organisasi berpengaruh terhadap kepuasan kerja}

Variabel Iklim organisasi terhadap kepuasan kerja guru Madrasah Aliyah Negeri (MAN) 1 Kebumen menunjukan pengaruh yang signifikan yaitu $\mathrm{t}_{\text {hitung }} 5,512>\mathrm{t}_{\text {tabel }} 2,000$ dengan tingkat signifikansi $0,000<0,05$, ini berarti variabel Iklim organisasi berpengaruh signifikan terhadap kepuasan kerja. Implikasi manajerial dari penelitian ini adalah diperlukannya usaha mempertahankan dan meningkatkan kualitas kepala sekolah, memperlancar komunikasi, memperkuat rasa tanggung jawab, meningkatkan partisipasi dan pengendalian internal/eksternal guru supaya kepuasan kerja guru Madrasah Aliyah Negeri (MAN) 1 Kebumen meningkat. Hasil penelitian ini sesuai dengan penelitian Nasution (2018), Darmadi (2016) dan Liana (2012) yang menemukan pengaruh signifikan Iklim organisasi terhadap kepuasan kerja.

\section{$\mathrm{H}_{2}$ : Green Product berpengaruh terhadap Keputusan Pembelian}

Pengujian hipotesis pertama dilakukan untuk mengetahui pengaruh Green Product terhadap Keputusan Pembelian. Hasil dengan penelitian menunjukan ada pengaruh Green Product terhadap Keputusan Pembelian dengan hasil uji t coefficients beta diperoleh nilai 0,415 dengan $\mathrm{t}_{\text {hitung }}$ sebesar $3,943>\mathrm{t}_{\text {tabel }}$ sebesar 1,985 dan taraf signifikan $0,00<0,05$. Kondisi ini menunjukkan bahwa Green Product berpengaruh positif terhadap Keputusan Pembelian Tupperware di Kebumen. Hal tersebut menunjukan bahwa jika green Product yang dilakukan oleh pemasar Tupperware dengan baik dan benar maka akan menimbulkan keputusan pembelian yang baik terhadap Tupperware

Selanjutnya penelitian ini sejalan dengan hasil penelitian terdahulu yang dilakukan oleh Pratama pada tahun 2013 dengan judul "Pengaruh Green Product dan Green Advertising terhadap Keputusan Pembelian Konnsumen (Studi pada Konsumen Supermarket Superindor Cabang Metro Bandung).Hasil penelitian menunjukan bahwa Green Product berpengaruh positif terhadap Keputusan Pembelian.

\section{$\mathrm{H}_{3}$ : Green Brand berpengaruh terhadap Keputusan Pembelian}

Pengujian hipotesis kedua dilakukan untuk mengetahui pengaruh Green Brand terhadap Keputusan Pembelian. Berdasarkan hasil uji $\mathrm{t}$ coefficients beta diperoleh nilai 0,202 dengan $t_{\text {hitung }}$ sebesar 2,926>t $t_{\text {tabel }}$ sebesar 1,985 dan taraf signifikansi $0,000<0,05$. Kondisi ini menunjukkan bahwa Green Brand berpengaruh positif terhadap Keputusan Pembelian pada Tpperware di Kebumen. Hal tersebut menunjukan bahwa jika green Brand yang dilakukan oleh pemasar Tupperware dengan baik dan benar maka akan menimbulkan keputusan pembelian yang baik terhadap Tupperware

Selanjutnya penelitian ini sejalan dengan hasil penelitian terdahulu yang dilakukan oleh Almaulidta pada tahun 2015 dengan judul "Pengaruh Green Brand terhadap Keputusan Pembelian dan Kepuasan Konsumen (Survei pada Mahasiswa Program Strata 1 Fakultas Ilmu Administrasi Universitas Brawijaya yang Menggunakan Produk Elektronik Merek Sony)". Hasil penelitian ini yaitu Green Brand berpengaruh positif dan signifikan terhadap Keputusan Pembelian.

\section{PENUTUP}

\section{Simpulan}

Pengujian hipotesis dalam uji t menunjukkan bahwa semua variabel berpengaruh signifikan secara parsial/sendirisendiri terhadap kepuasan kerja guru MAN 1 Kebumen, sehingga diharapkan MAN 1 Kebumen lebih meningkatkan kondisi terkait iklim organisasi, motivasi intrinsik dan motivasi ekstrinsik yang lebih baik agar kepuasan kerja guru MAN 1 Kebumen tetap maksimal. Dalam uji F juga menunjukkan nilai $\mathrm{F}$ yang signifikan yang menunjukkan diperlukannya perbaikan variabel iklim organisasi, motivasi intrinsik dan motivasi ekstrinsik, karena ketiga variabel tersebut berpengaruh signifikan secara bersamasama terhadap kepuasan kerja guru MAN 1 Kebumen.

\section{$\mathrm{H}_{2}$ : Green Advetising berpengaruh terhadap Keputusan Pembelian}

Pengujian hipotesis ketiga dilakukan untuk mengetahui pengaruh Green Advertising terhadap Keputusan Pembelian. Berdasarkan hasil uji t coefficients beta diperoleh nilai 0,340 dengan $\mathrm{t}_{\text {hitung }}$ sebesar 5,522> $\mathrm{t}_{\text {tabel }}$ sebesar 1,985 dan taraf signifikansi $0,000<0,05$. Kondisi ini menunjukkan bahwa Green Advertising berpengaruh signifikan terhadap Keputusan Pembelian. Hal tersebut menunjukan bahwa jika green Advertising yang dilakukan oleh pemasar Tupperware dengan baik dan benar maka akan menimbulkan keputusan pembelian yang baik terhadap Tupperware

Selanjutnya penelitian ini sejalan dengan hasil penelitian terdahulu yang dilakukan oleh Praharjo et al pada tahun 2013 dengan judul "Pengaruh Green Advertising terhadap Persepsi Tentang Green Brand dan Keputusan Pembelian (Survei Pada Mahasiswa Fakultas Ilmu Administrasi Angkatan 2010/2011 Universitas Brawijaya Konsumen Air Minum Kemasan Merek Ades)". Hasil penelitian ini yaitu Green Advertising berpengaruh positif dan signifikan terhadap keputusan pembelian.

Berdasarkan hasil uji Adjusted R2 pada penelitian yang diperoleh yaitu sebesar 0,738 . Hal ini menunjukkan bahwa keputusan pembelian dipegaruhi oleh variabel Green Product, Green Brand, dan Green Advertising sebesar $73,8 \%$, sedangkan sisanya sebesar $26,2 \%$ dipengaruhi factor lain yang tidak termasuk dalam penelitian ini. Hasil in membuktikan bahwa variabel keputusan pembelian Tupperware belum bisa sepenuhnya dijelaskna oleh variabel Green Product, Green Brand, dan 
Green Advertising karena nilainya msih di bawah $100 \%$. Diharapkan untuk penelitian selanjutnya untuk menambahkan variabel lain seperti Kualitas Produk Tupperware agar nilai koefisien determinasinya bertambah besar lagi.

\section{Saran}

1. Green Product memiliki pengaruh secara signifikan terhadap keputusan pembelian. Berdasarkan analisa tersebut saran yang diberikan kepada perusahaan yaitu agar perusahaan Tupperware diharapkan dapat mempertahankan dan meningkatkan kepercayaan masyarakat tentang produk yang ramah lingkungan yang bukan hanya memperhatikan kualitas, namun juga memperhatikan aspek lingkungan. Karena semakin tinggi kepercayaan masyarakat akan green product maka akan meningkatkan keputusan pembelian.

2. Green Brand memiliki pengaruh secara signifikan terhadap keputusan pembelian. Berdasarkan analisa tersebut saran yang diberikan kepada perusahaan yaitu agar perusahaan Tupperware diharapkan dapat lebih memperkenalkan bahwa produk-produk Tupperware adalah produk yang berlabelkan ramah lingkungan, agar masyarakan lebih mengetahui Tupperware bukan hanya produk yang berkualitas namun juga ramah lingkungan.

3. Green Advertising memiliki pengaruh secara signifikan terhadap keputusan pembelian. Berdasarkan analisa tersebut saran yang diberikan kepada perusahaan yaitu agar perusahaan Tupperware diharapkan dapat lebih meningkatkan kreativitas dalam pembuatan iklan agar dapat menarik dan mempengaruhi orang yang melihatnya. Seperti mejelaskan pentingnya produk ramah lingkungan untuk kesehatan kita, dan mengajak masyarakat untuk hidup sehat. Selain itu, perusahaan diharapkan melakukan penayangan iklan di TV supaya masyarakat lebih mengetahui lebih banyak tentang manfaat Tupperware.

\section{Bagi Peneliti Selanjutnya}

1. Penelitian selanjutnya disarankan untuk melakukan penelitian dengan menambah variabel-variabel lain seperti kepuasan konsumen, kepercayaan konsumen atas merek atau variabel lainnya

2. Bagi peneliti selanjutnya diharapkan dapat memperluas cakupan wilayah penelitian.

\section{DAFTAR PUSTAKA}

Alniacik, Umit \& Yilmaz, Cengiz. (2012). "The Effectiveness of Green Advertising: Influences of Claim Specificity, Product's Environmntal Relevance and Consumers' Pro-Enviromental Orientation". Amfiteatru Economic (Volume 16 Nomor 31). Hlm. 207-222.
Amirullah. (2002). Perilaku Konsumen. Yogyakarta:

Graha Ilmu.

Ankit, Gandhi \& Mayur, Rao. (2013). “Green Marketing: Impact of Green Advertising on Consumer Purchase Intention". Advances in Management (Volume 6 Nomor 9).

Banerjee, S., Gulas, C.S, \& Iyer, E. (1995). "Shades of Green: A Multidimensional Analysis of Enviromental Advertising. Journal of Advertising (Volume 24 Nomor 2).

Dahlstrom, Robert. (2011). Green Marketing Management. USA: South-Western Cengage Learning.

D'Souza, C., Taghian, M., Lamb, P., and Peretiatkos, R. (2006). "Green Products and Corporate Strategy: An Empirical Investigation". Society and Business Review. Vol. 1 Iss: 2

Gujarati, Damodar N. (2003). Ekonometrika Dasar. Jakarta : Erlangga. Hadi, Sutrisno. (2002). Metode Penelitian. Yogyakarta: Pascasarjana UGM.

Handayani, Novita Tri. (2012). "Pengaruh Atribut Produk terhadap Loyalitas Pelanggan Green Product Sepeda Motor Honda Injection". Management Analysis Journal (Volume 1 Nomor 2). Hlm. 1-2.

http://www.topbrands-awards.com tanggal 26 Februari 2019

Keller, Kevin Lane. (1993). "Conceptualing, Measuring, and Managing Customer- Based Brand Equity". Journal of Marketing (Volume 57 Nomor 1)

Kotler, Philip \& Amstrong, Gary. (2012). Principle of Marketing, Global Edition, 14th Edition. USA: Pearson Education Limited.

Makower, J., Elkington, J., Hailes, J.(1993). The Green Consumer.USA: Penguin Group.

Mourad, Maha \& Ahmed, Yaser. (2012). "Perception of Green Brand in an Emerging Innovative Market". European Journal of Innovation Management (Volume 15 Nomor 4). Hlm. 514-537.

Oentoro, Deliyanti. (2010). Manajemen Pemasaran Modern. Yogyakarta: LaksBang Pressindo.

Oyewole, Philemon. (2001). "Social Costsof Environmental Justice Associated with The Practice of Green Marketing”. Journal of Business Ethics (Volume 29, No 3).

Praharjo, A., Suharyono, \& Wilopo. (2013). "Pengaruh Green Advertising terhadap Persepsi Tentang Green Brand dan Keputusan Pembelian (Survei Pada Mahasiswa Fakultas Ilmu Administrasi 
Angkatan 2010/2011 Universitas Brawijaya Konsumen Air Minum Kemasan Merek Ades)". Jurnal Universitas Brawijaya (Volume 4 Nomor 2). Hlm. 1

Prakash, Aseem. (2002). “Green Marketing, Public Policy and Managerial Strategies". Business Startegy and the Enviroment (Volume 11 Nomor 5). Published online in Wiley InterSciene (www.intersciene.wiley.com)

Pratama, Briyan Timur Nanda.(2013). "Pengaruh Green Product dan Green Advertising terhadap Keputusan Pembelian (Survei pada Konsumen Supermarket Superindo cabang Metro Bandung). www.unikom.ac.id.

Pujari, D., Wright, G., \& Peattie, K. (2003). “Green and Competitive Influences on Environmental New Product Development Performance". Journal of Business Research (Volume 56).

Purnama, James \& Nurhadi. (2014). "Pengaruh Produk Ramah Lingkungan, Atribut Merek Hijau, Iklan Peduli Lingkungan dan Presepsi Harga Premium terhadap Keputusan Pembelian Produk AMDK”. Jurnal Fakultas Ekonomi Tahun 2014. Hlm. 1-9.

Rath, Ramesh Chandra. (2013). “An Impact of Green Marketing on Practices of Supply Chain Management in Asia: Emerging Economic Opportunities and Challenges. International Journal of Supply Chain Management (Volume 2 Nomor 1).

Schiffman, Leon G. dan Leslie Lazar Kanuk. (2007). Perilaku Konsumen. Jakarta: Indeks.Simamora, Henry. (2000). Akuntansi Basis Pengambilan Keputusan Bisnis. Jakarta: Salemba Empat.

Singarimbun, M., dkk. (2006). Metode Penelitian Survei. Jakarta: Pustaka LP3S.

Situmorang, James R. (2011). "Pemasaran Hijau yang Semakin Menjadi Kebutuhan dalam Dunia Bisnis". Jurnal Administrasi Bisnis (Volume 7 Nomor 2. Hlm. 135. 